\title{
Morus alba Improves Hyperglycemia, Hyperlipidemia and Oxidative Stress in Streptozotocin-Induced Diabetic Nephropathy
}

\author{
Swathi Putta ${ }^{1+}$, Lingaswamy Bantu ${ }^{1+}$, Nagendra Sastry Yarla ${ }^{2 *}$, Rambabu Undi ${ }^{3}$ \\ ${ }^{1}$ Pharmacology Division, A.U. College of Pharmaceutical Sciences, Andhra University, Visakhapatnam \\ Department of Biotechnologyc and Bioinformatics, School of Life Sciences, University of Hyderabad, Hyderabad-500046, Telangana, India \\ Department of Biochemistry, School of Life Sciences, University of Hyderabad, Hyderaabad-500046, Telangana, India \\ +: Equal Contribution
}

Address for Correspondence: Nagendra Sastry Yarla, sastryyn@gmail.com

Received:

13.06.2018

Accepted:

23.06.2018

Keywords Blood glucose; Morus alba; Oxidative stress; Streptozotocin.

\begin{abstract}
Diabetic nephropathy (DN) is one the leading causes of death in diabetic patients. Morus alba, belongs to the family Moraceae is used traditionally to treat diabetic alignments, however its scientific validation is lacking. The present study was designed to determine if the hypoglycemic, antioxidant and hypolipidemic activities of Morus alba ethanolic leaf extract (EMA) could improve the renal function in hyperglycemia. Blood glucose, serum parameters such as glycated hemoglobin (HbAlc), bilirubin, albumin, creatinine, total protein, urea, lipid profile, and urine parameters such as urine protein, creatinine and volume and renal antioxidant enzymes like SOD, CAT, GSH and MDA were estimated at the end of 12 weeks study period. Kidney histopathology was also done. The treatment with EMA showed significant $(p<0.05)$ reduction in the elevated blood glucose, HbA1c, kidney function parameters and lipid profile in STZ induced diabetic rats. In STZ induced diabetic rats showed protein urea, hyperurecemia and increased urine volume was found to be reverting back to normal values significantly. Treatment with EMA exerted improvement in antioxidant enzymes as SOD, CAT, GSH and reduction in MDA level. Histopathology reveals, EMA showed marked amelioration of glomerulosclerosis caused by STZ. The results suggested that EMA has reduced development of diabetic nephropathy in streptozotocin-induced diabetic rats and could have beneficial effect in reducing the progression of diabetic nephropathy. () 2019 iGlobal Research and Publishing Foundation. All rights reserved.
\end{abstract}

Cite this article as: Putta, S.; Bantu, L.; Yarla, N.S.; Undi, R. Morus alba improves hyperglycemia, hyperlipidemia and oxidative stress in streptozotocin-induced diabetic nephropathy. Indo Global J. Pharm. Sci., 2019; 9(1): 25-31. DOI: http://doi.org/10.35652/IGJPS.2019.9104 .

\section{INTRODUCTION}

Diabetes mellitus is a chronic and progressive metabolic disease characterized by hyperglycemia due to insulin deficiency, or resistance, or both. Besides hyperglycemia, several other symptoms, including hyperlipidemia, are involved in the development of microvascular and macrovascular complication of diabetes. According to the latest survey in 219 countries, among people egad 20 to 79 years, 382 million people have diabetes mellitus and it is estimated that this number will reach 592 million in 2035 [1]. Diabetic nephropathy (DN) is a major cause of end stage renal failure worldwide. DN has not been traditionally considered an inflammatory disease; however, recent studies have shown that kidney inflammation is crucial in promoting the development and progression of DN [2-3]. 


\section{Indo Global Journal of Pharmaceutical Sciences, 2019; 9(1): 25-31}

Reactive oxygen species play an important role in high glucose induced renal injury [4]. Free radicals are capable of damaging cellular molecules, DNA, proteins, and lipids leading to altered cellular functions. Many recent studies reveal that antioxidants capable of neutralizing free radicals are effective in preventing experimentally induced diabetes in animal models [5].

Herbal medicines are naturally occurring; plant-derived substances with minimal or no industrial processing that have been used to treat illness within local or regional healing practices. For a long time, herbal medicines or their extracts have been used to cure various diseases, because plant products are frequently considered to be less toxic and free from side effects than synthetic ones. Therefore, studies with plant extracts are useful to understand their efficacy, mechanism of action and safety for treatment and management of diabetes.

Numerous plants have been reported to possess hypoglycemic activity and diabetic nephropathy. Some reported plant sources are Ginkgo biloba [6], Fragaria ananassa [7], Moringa oleifera [8], Cladophora glomerata [9], Garcinia indica [5], Ocimum gratissimum [10], Astragalus membranaceus [11] and Trigonella foenumgracum [12]. Reports indicated herbal inventions play a pivotal role in the treatment of diabetes and diabetic nephropathy.

The present investigation was focused on Morus alba (Moraceae). Morus alba reported pharmacological activities related to in vitro antioxidant activity [13], hypoglycemic activity in alloxane induced diabetic rats as $\alpha$-amylase inhibitory activity [14] and protective action on ocular function [15] due to the presence of triterpenes (lupeol) sterols ( $\beta$ - sitosterol), bioflavonoids (rutin, moracetin, quercetin-3triglucoside and isoquercitrin), coumarins, volatile oil, alkaloids, amino acids and organic acids. Morus alba leaves contain rutin, quercetin and apigenin as bioactive constituents [16]. Considering the antioxidant activity and hypoglycemic properties of Morus alba, this study was designed to evaluate the ameliorator effect of Morus alba on oxidative stress induced diabetic nephropathy in diabetes rats induced by streptozotocin.

\section{MATERIALS AND METHODS}

\section{Plant material}

Fresh leaves of Morus alba (Mulburry) were obtained during winter season from the rural areas of Visakhapatnam and identified and authenticated (voucher specimen No. 12621) by plant taxonomist, department of Botany, Andhra University, India.

\section{Preparation of plant extract}

The fresh leaves are washed and cut into small pieces and dried under sunshade for 6 to 7 days and coarsely powdered. The powder was extracted using Soxhlet apparatus with ethanol $2000 \mathrm{~mL}$. The methanol was distilled condensed using rotatory evaporator and stored in desiccators. The powder of the extract was suspended in appropriate solvent system.

\section{Chemicals}

Streptozotocin was procured from Sigma Co. USA, metformin from USV Limited, Maharashtra, while other chemicals used were of analytical grade obtained from E. Merck and Himedia, India.

\section{Animals and treatment}

Male Wistar rats (150 180 g) were used. These were bred in our animal facility and housed in an air-conditioned room (approximately $22^{\circ} \mathrm{C}$ ) with controlled lighting $12: 12 \mathrm{~h}$ light/dark cycle. The animals were maintained with pelleted, while tap water was available ad libitum. The study has got the clearance from the Institutional Animal Ethical Committee (IAEC) the Committee for the Purpose of Control and Supervision of Experiments on Animals (CPCSEA). Rats were acclimatized to the environment for 15 days prior to the experiment; animals were divided into five groups. Each group contains 6 rats. Fasted animals were deprived of food for at least $16 \mathrm{~h}$ but allowed free access to water. The first group was used as control and received $\mathrm{H}_{2} \mathrm{O}$ as vehicle. The second group received a single dose of STZ (60 mg/kg b.wt) and dissolved in citrate buffer and was divided into four subgroups after establishing of the diabetes for 1 week. The first subgroup was kept as a diabetic control while the second, third, and fourth subgroups received orally $1.0 \mathrm{~mL}$ of metformin $(500 \mathrm{mg} / \mathrm{kg}$ b.wt), EMA $(150 \mathrm{mg} / \mathrm{kg})$ and EMA $(300 \mathrm{mg} / \mathrm{kg}$ ) respectively by gastric intubation daily for 12 weeks.

\section{Preparation of samples}

The rats were then ether anesthetized, decapitated and blood sample collected in plain and heparined tubes. From the clotted blood at room temperature, serum was collected after centrifugation (3000 rpm, $10 \mathrm{~min}$ ) and used to determine the biochemical parameters. Twenty four hour urine samples were collected using metabolic cages and analyzed. The animals were kept individually in metabolic cages, and they were given only water.

The kidney were removed, weighed and placed immediately in ice-cold buffer $(0.25 \mathrm{M}$ sucrose, $10 \mathrm{mM}$ Tris and $0.3 \mathrm{mM}$ EDTA; $\mathrm{pH}$ 7.4) and washed thoroughly with distilled water to remove blood. The kidneys were homogenized using a Teflon 


\section{Indo Global Journal of Pharmaceutical Sciences, 2019; 9(1): 25-31}

homogenizer. The total homogenate was used for estimation of lipid profile and MDA. The homogenate was centrifuged (15 min, $15000 \mathrm{rpm}$ ), the whole supernatant removed and frozen at $-20^{\circ} \mathrm{C}$ for estimation of antioxidant enzymes.

\section{Biochemical Estimations}

Fasting blood glucose levels were estimated by using GOD/POD method [17]. Glycosylated haemoglobin was determined by the method of [18], cholesterol and triglyceride (TG) levels were measured using standard methods [19-21] and HDL-cholesterol [22], bilurubin [23], total protein [24] and albumin [25]. At the end of the 12 week treatment period rats were sacrificed and kidneys were used for histopthological examination.

\section{Enzyme estimations in Kidney}

Superoxide dismutase was measured according to the method described by [26]; catalase was estimated by the method of [27], reduced glutathione measured by method of [28], and melanoldehyde was measured by the method of [29].

\section{Histopathology}

Renal tissues were collected after animal sacrifice, fixed in $10 \%$ formalin, processed routinely, and embedded in paraffin. Sections $5 \mu \mathrm{m}$ thick were prepared and stained with hematoxylin and eosin (H\&E) dye for microscopic investigation [30]. The stained sections were examined and photographed under a light microscope.

\section{Statistical analysis}

Values are mean \pm SEM for six rats in each group, and significance of the differences between mean values was determined by Bonferroni-post test. The levels of significance were evaluated with $p$ values.

\section{RESULTS AND DISCUSSION}

Tight control of blood glucose can reduce clinical complications in diabetic patients. However, alternative treatment strategies are required to prevent the oxidative stress complications such as diabetes. It is well documented that modulations of oxidative stress through treatment with antioxidants can effectively reduce the development of diabetes [31].

In the present study, diabetes mellitus was induced in rats through a STZ injection that causes the destruction of $\beta$-cells of islets of Langerhans, as proposed by many authors [32]. This effect was represented in the current study through the elevation of blood glucose in STZ induced diabetic control rats. The administration of EMA showed significant $(\mathrm{p}<0.05)$ reduction of blood glucose levels (Table 1) accompanied with reduction in glycosylated heamoglobin levels (Table 2). This might be due to Morus alba showed to reduce food intake and blood glucose absorption levels in STZ induced diabetic rats [33].

Hypercholesterolemia, hypertriglyceridemia and enhanced glomerular lipid synthesis have been implicated in diabetic glomerulosclerosis and known to exercebate kidney diseases [34]. Several groups of hypoglycaemic drugs are currently available to treat diabetes [35]. The abnormal high concentration of serum lipids in diabetes is mainly due to the increase in the mobilization of free fatty acids from the peripheral depots since insulin inhibits the hormone sensitive lipase [5]. In EMA treated diabetic rats shown to normalize the lipid levels (reduction of TG, TC, LDL, VLDL and elevation of HDL) as compared to the STZ induced hyperlipidemia (elevation of TG, TC, LDL, VLDL and reduction of HDL both in serum and kidney homogenate as shown in Figures 1 and 2. The hyperglycemic effect of EMA could indirectly be related to beneficial action against diabetic hypercholesterolemia, hypertriglyceridemia.

Diabetic nephropathy in uncontrolled diabetes is a serious micro-vascular complication leading to glycosylation of renal basement membranes and result in hyperproteinuria, hypercreatinemia, and increased urinary excretion of creatinine, urea, and uric acid [36-37]. Normally, the kidney excretes creatinine and only low amount of low-molecular weight protein passes through the glomerulus [38], whereas urea and uric acid are reabsorbed by the proximal tubule [39]; [5]. EMA showed significant $(p<0.05)$ reduction of bilirubin, creatinine and elevation of protein levels than those of nondiabetic group, implying the presence of diabetic kidney disease with renal hyperfiltration due to STZ induction (Table 2). We observed that repeated treatment with EMA could attenuate hyperproteinuria, hypercreatinemia as well as ameliorate the loss of renal function and glomerular hyperfiltration in STZ-diabetic rats. Due to improved the filtration function and tubular reabsorption by EMA, urinary creatinine, urea, and uric acid level were controlled significantly $\mathrm{p}<0.05$ (Table 3 ).

Oxidant stress markers (CAT, SOD, GSH and MDA), which are critical factors in the progression of diabetic nephropathy, are increased by inflammatory mechanisms of injury in the kidney [40]. Among antioxidative enzymes, SOD catalyzes dismutation of the superoxide anion into hydrogen peroxide, while GSH both detoxifies hydrogen peroxides and converts lipid hydroperoxides to nontoxic alcohols; thus, antioxidant enzymes activities could reflect antioxidant defense status [41]. In this work, the reduced activities of SOD, CAT and 
Indo Global Journal of Pharmaceutical Sciences, 2019; 9(1): 25-31

Table 1: Effect of Morus alba on blood glucose levels in STZ induced diabetic rats during different intervals of 12 weeks study period.

\begin{tabular}{|c|c|c|c|c|c|}
\hline \\
\hline $\begin{array}{c}\text { Treatment } \\
\text { (mg/kg) }\end{array}$ & Oday & 3 week & 6 week & 9 week & 12 week \\
\hline Control & $108.23 \pm 2.71$ & $97.16 \pm 1.21^{\mathrm{ns}}$ & $101.66 \pm 3.19^{\mathrm{ns}}$ & $99.33 \pm 2.03^{\mathrm{ns}}$ & $96.23 \pm 4.79^{\mathrm{ns}}$ \\
\hline D.Control & $325 \pm 4.93$ & $316.45 \pm 4.50^{\mathrm{ns}}$ & $333.16 \pm 5.66^{\mathrm{ns}}$ & $319.16 \pm 5.23^{\mathrm{ns}}$ & $324.83 \pm 4.11^{\mathrm{ns}}$ \\
\hline Standard & $321.11 \pm 6.53$ & $213.13 \pm 2.18^{*}$ & $134.23 \pm 3.17^{* *}$ & $109.32 \pm 2.36^{* * *}$ & $92.50 \pm 2.99^{* * *}$ \\
\hline EMA( 300mg/kg) & $314.13 \pm 4.88$ & $198.66 \pm 3.14^{* *}$ & $126.46 \pm 1.84^{* *}$ & $98.13 \pm 4.16^{* * *}$ & $87.26 \pm 4.55^{\text {**** }}$ \\
\hline
\end{tabular}

Number of rats per group $=6$; data on each parameter were analyzed by one-way ANOVA followed by Dunnet's test; ${ }^{*} P<0.05, * * P<$ $0.01, * * * P<0.001$ as compared with diabetic control

Table 2: Effect of Morus alba on serum parameters in STZ induced diabetic rats at the end of 12 weeks study period.

\begin{tabular}{|c|c|c|c|c|c|}
\hline $\begin{array}{c}\text { Treatment } \\
(\mathbf{m g} / \mathbf{k g})\end{array}$ & $\begin{array}{c}\text { HbA1c } \\
(\boldsymbol{\%})\end{array}$ & $\begin{array}{c}\text { T.bilirubin } \\
(\mathbf{m g} / \mathbf{d L})\end{array}$ & $\begin{array}{c}\text { Creatinine } \\
(\mathbf{m g} / \mathbf{d L})\end{array}$ & $\begin{array}{c}\text { Total protein } \\
(\mathbf{m g} / \mathbf{d L})\end{array}$ & $\begin{array}{c}\text { Albumin } \\
(\mathbf{m g} / \mathbf{d L})\end{array}$ \\
\hline Control & $4.09 \pm 0.23^{* *}$ & $0.72 \pm 0.016^{*}$ & $0.68 \pm 0.02^{*}$ & $6.93 \pm 0.14 *$ & $3.35 \pm 0.09 *$ \\
\hline D.Control & $11.43 \pm 0.56$ & $1.78 \pm 0.042$ & $1.92 \pm 0.03$ & $3.88 \pm 0.34$ & $7.20 \pm 0.10$ \\
\hline Standard & $3.42 \pm 0.16^{* * *}$ & $0.77 \pm 0.025^{*}$ & $0.69 \pm 0.02^{*}$ & $6.13 \pm 0.67 *$ & $3.86 \pm 0.06^{*}$ \\
\hline EMA (150mg/kg) & $5.02 \pm 0.25^{*}$ & $0.92 \pm 0.016^{*}$ & $0.89 \pm 0.04^{*}$ & $7.90 \pm 0.24 *$ & $5.13 \pm 0.11 *$ \\
\hline EMA( 300mg/kg) & $4.16 \pm 0.54^{* *}$ & $0.73 \pm 0.013^{*}$ & $0.71 \pm 0.03 * *$ & $6.06 \pm 0.18^{*}$ & $3.99 \pm 0.12^{* *}$ \\
\hline
\end{tabular}

Number of rats per group $=6$; data on each parameter were analyzed by one-way ANOVA followed by Dunnet's test; ${ }^{*} P<0.05, * * P<$ $0.01, * * * P<0.001$ as compared with diabetic control

Table 3: Effect of Morus alba on urine parameters in STZ induced diabetic rats at the end of 12 weeks study period

\begin{tabular}{|c|c|c|c|c|c|}
\hline $\begin{array}{c}\text { Treatment } \\
(\mathbf{m g} / \mathbf{k g})\end{array}$ & $\begin{array}{c}\text { Creatinine } \\
(\mathbf{m g} / \mathbf{d L})\end{array}$ & $\begin{array}{c}\text { Urine volume } \\
\mathbf{( m l} / \mathbf{2 4 h r s})\end{array}$ & $\begin{array}{c}\text { Ccr } \\
(\mathbf{m l} / \mathbf{h r s})\end{array}$ & $\begin{array}{c}\text { Uric acid } \\
(\mathbf{m g} / \mathbf{d L})\end{array}$ & $\begin{array}{c}\text { Urea } \\
(\mathbf{m g} / \mathbf{d L})\end{array}$ \\
\hline Control & $0.61 \pm 0.05$ & $09.42 \pm 0.41$ & $1.31 \pm 0.79$ & $4.09 \pm 0.32$ & $22.03 \pm 0.77$ \\
\hline D.Control & $1.68 \pm 0.03$ & $26.52 \pm 0.85$ & $6.61 \pm 0.49$ & $8.72 \pm 0.18$ & $39.46 \pm 0.94$ \\
\hline Standard & $0.69 \pm 0.04 * *$ & $14.43 \pm 0.43 *$ & $1.84 \pm 0.11 * *$ & $4.23 \pm 0.34 *$ & $26.89 \pm 0.77 * *$ \\
\hline EMA (150mg/kg) & $1.11 \pm 0.04^{*}$ & $18.17 \pm 0.32 *$ & $2.73 \pm 0.20 *$ & $5.79 \pm 0.21 *$ & $32.23 \pm 0.93 *$ \\
\hline EMA( 300mg/kg) & $0.65 \pm 0.04^{* *}$ & $12.09 \pm 0.49 *$ & $1.89 \pm 0.21 * *$ & $4.96 \pm 0.44 *$ & $27.13 \pm 0.87 * *$ \\
\hline
\end{tabular}

Number of rats per group $=6$; data on each parameter were analyzed by one-way ANOVA followed by Dunnet's test; $* P<0.05,{ }^{* *} P<$ $0.01, * * * P<0.001$ as compared with diabetic control

Table 4: Effect of Morus alba on antioxidant parameters in STZ induced diabetic rats at the end of 12 weeks study period

\begin{tabular}{|c|c|c|c|c|}
\hline $\begin{array}{c}\text { Treatment } \\
\text { (mg/kg) }\end{array}$ & $\begin{array}{c}\text { SOD } \\
\text { (U/mg of protein) }\end{array}$ & $\begin{array}{c}\text { CAT } \\
\text { (U/mg of protein) }\end{array}$ & $\begin{array}{c}\text { GSH } \\
\text { (mg/100g } \\
\text { tissue) }\end{array}$ & $\begin{array}{c}\text { MDA } \\
\text { (U/mg of } \\
\text { protein) }\end{array}$ \\
\hline Control & $10.23 \pm 1.23$ & $34.23 \pm 1.86$ & $20.46 \pm 0.37$ & $132.16 \pm 0.88$ \\
\hline D.Control & $4.65 \pm 1.01$ & $17.64 \pm 1.34$ & $15.65 \pm 0.17$ & $246.79 \pm 2.13$ \\
\hline Standard & $9.46 \pm 0.89^{* *}$ & $32.16 \pm 0.68^{* * *}$ & $21.13 \pm 0.26^{* * *}$ & $139.23 \pm 3.77^{* * *}$ \\
\hline EMA (150mg/kg) & $7.26 \pm 0.74^{* *}$ & $28.42 \pm 0.97^{* *}$ & $20.11 \pm 0.41^{* *}$ & $221.85 \pm 2.47^{*}$ \\
\hline EMA( 300mg/kg) & $10.16 \pm 1.06^{* * *}$ & $31.09 \pm 1.35^{* *}$ & $20.16 \pm 0.74^{* * * *}$ & $143.92 \pm 0.49^{* * *}$ \\
\hline
\end{tabular}

Number of rats per group $=6$; data on each parameter were analyzed by one-way ANOVA followed by Dunnet's test; $* P<0.05,{ }^{* *} P<$ $0.01, * * * P<0.001$ as compared with diabetic control 
Indo Global Journal of Pharmaceutical Sciences, 2019; 9(1): 25-31

GSH in kidney of STZ-diabetic rats were elevated significantly $(\mathrm{p}<0.05)$ by EMA (Table 4). The classical formula protecting kidney of diabetic rats from oxidative damage by enhancing enzymatic antioxidative defense systems could be considerable. A significant increase in MDA, an index of endogenous lipid peroxidation, has been shown under diabetic conditions [42]. From this view point, the prevention of oxidative stress-related hyperlipidemia and/or lipid peroxidation is considered crucial in preventing disorders associated with diabetes [43]. The EMA showed significant reduction in MDA levels in kidney homogenate of STZ induced diabetic rats as shown in table 4 . The in vivo free radical scavenging activity of Morus alba might due to the presence of quercetin, 5,7-dihydroxycoumarin 7-methyl ether, oxyresveratrol and mulberroside as reported earlier by [16], [44-45].

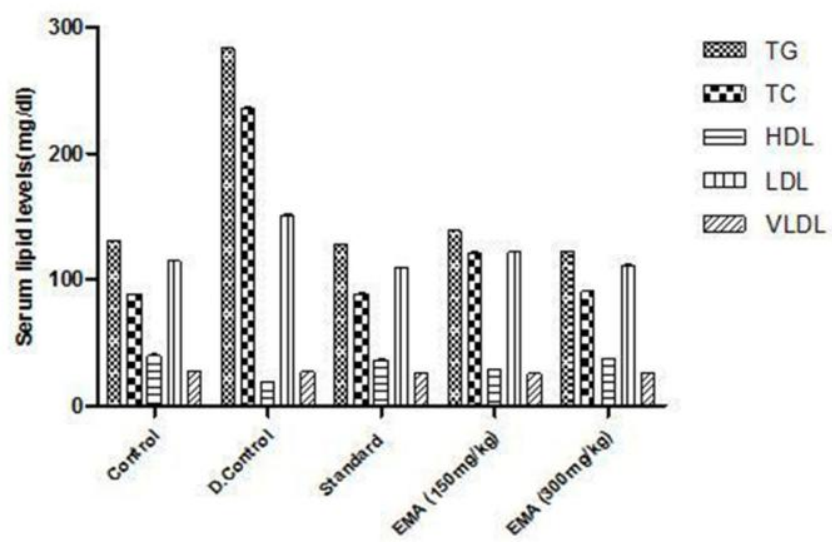

Figure 1: Effect of Morus alba on serum lipid levels in STZ induced diabetic rats at the end of 12 weeks study period.

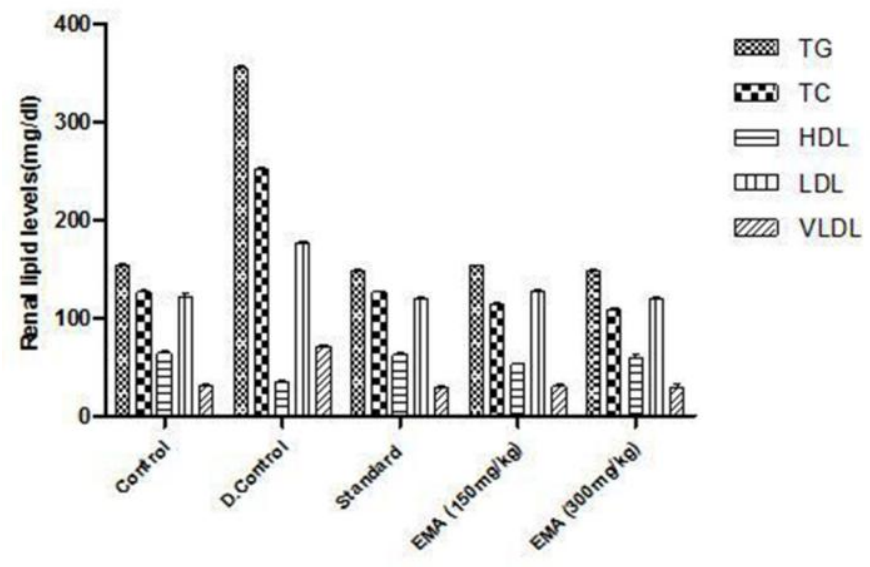

Figure 2: Effect of Morus alba on renal lipid levels in STZ induced diabetic rats at the end of 12 weeks study period.

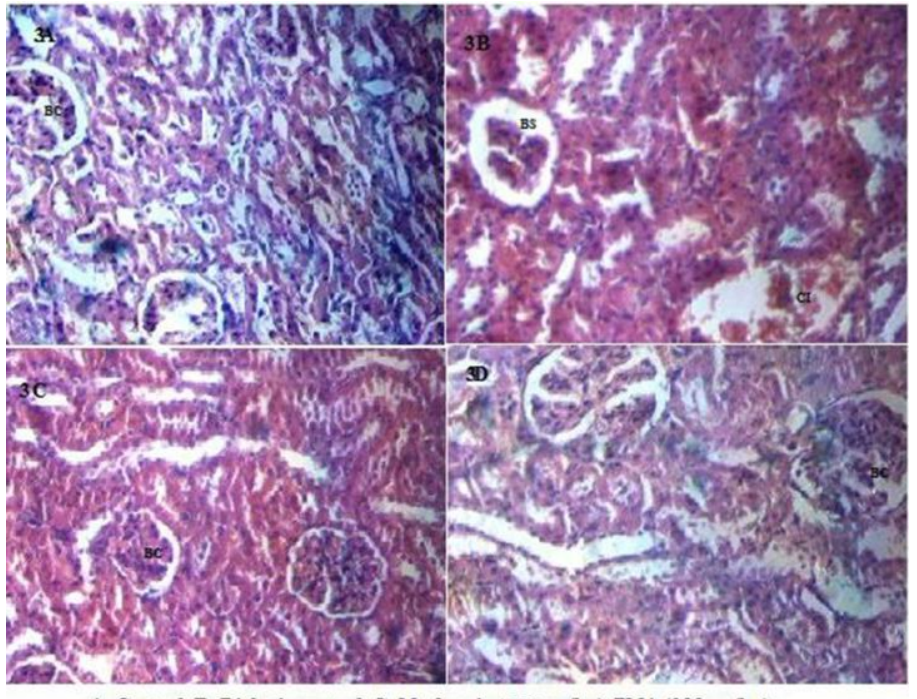

A: Control, B: Diabetic control, C: Metformin (150mg/kg), EMA $(300 \mathrm{mg} / \mathrm{kg})$

Figure 3: Effect of Morus alba on histopathology of kidney. 3A: Normal glomeruli and a compact tissue appearance with bowmans capsule (BC); 3B: increased bowmans space (BS) and presence cellular infiltrates (CI) indicates cellular damage; 3C: Noticeable improvements in the tissue architecture were evident, and more visible glomeruli and fewer inflammatory cells were observed; 3D: absence of inflammatory cells, normal basement membrane.

The light microscopic examination of kidney of disease control group revealed the altered structure Bowman 's capsule by increasing bowman's space and presence of cellular infiltrates (Figure 3). The treatment with the EMA extract and metformin found to prevent the degenerative changes in STZ induced diabetic rats. It is reported several phytochemicals triterpenes, $\beta$ - Sitosterol, bioflavonoids coumarins and volatile oils [16] might be responsible for the antioxidant, antihyperglycemic and hyperlipidemic activities of Morus alba.

\section{CONCLUSION}

Morus alba decreased blood glucose levels (hypoglycemia), normalizing the lipid levels in both serum and kidney (dyslipidemia), reduction in both serum and urine parameters and increased antioxidant enzymes activities (antioxidant) in diabetic rats. And consequently could alleviate diabetic nephropathy.

\section{CONFLICT OF INTEREST}

Authors declare no conflicts of interest. 


\section{Indo Global Journal of Pharmaceutical Sciences, 2019; 9(1): 25-31}

\section{ACKNOWLEDGEMENT}

Dr. Swathi Putta acknowledges the University Grants Commission (UGC), New Delhi, No.F.15-1/201617/PDFWM-2015-17-AND-36497 (SA-II) to financial support for carrying out the research work. Nagendra Sastry Yarla (NSY) expresses his sincere gratitude to Dr. M.V.V.S. Murthy, President, GITAM University for his support and encouragement by providing necessary research facilities.

\section{REFERENCES}

1. L Guariguata, DR Whiting, I Hambleton. Global estimates of diabetes prevalence for 2013 and projections for 2035. Diabetes Research and Clinical Practice, 2014; 103(2):137-149.

2. AK Lim, GH Tesch. Inflammation in diabetic nephropathy. Mediators of Inflammation, 2012: 146154.

3. J Wada, H Makino. Inflammation and the pathogenesis of diabetic nephropathy. Clinical Science, 2013; 124:139-152.

4. D Bonnefont, JP Bastard, MC Jaudon, J Delattre. Consequences of diabetes status on the oxidant /antioxidant balance. Diabetes \& Metabolism, 2000; 26:163-76.

5. P Swathi, T Jagadeesh Kumar, K Eswar Kumar. Methanolic fruit extract of Garcinia indica ameliorates progression of diabetic nephropathy in Streptozotocin induced diabetic rats. International Journal of Biological \& Pharmaceutical Research, 2015; 6(1):12-18.

6. Q Lu, WZ Zuo, XJ Ji. Ethanolic Ginkgo biloba leaf extract prevents renal fibrosis through Akt/mTOR signaling in diabetic nephropathy. Phytomedicine, 2015; 22(12): 1071-8.

7. DS Ibrahim, MMA Abd El. Effect of strawberry (Fragaria ananassa) leaf extract on diabetic nephropathy in rats. International Journal Experimental Pathology, 2015; 96(2): 187-93

8. L Abdulrahman, M Al, AER Haddad. The antidiabetic effect of loe doses of Moringa oleifera Lam. seeds on Streptozotocin induced diabetes and diabetic nephropathy in male rats. BioMed Research International, 2015: 381040.

9. S Chutima, O Atcharaporn, S Naruwan, V Pornpun, P Anchalee, A Doungporn, S Sunhapas, C Varanuj. Antidiabetic and renoprotective effects of cladophora glomerata kützing extract in experimental type 2 diabetic rats: A potential nutraceutical product for diabetic nephropathy. Journal of Diabetes Research, 2015: 320167

10. EE Efiong, PE Ebong. Ocimum gratissimum and Moringa oleifera ameliorates diabetic nephropathy in a synergistic manner similar to insulin. Journal Pharmaceutical Chemical and Biological Scencesi. 2014; 2(2):158-165.

11. M Jiman K Eulsun, $\mathrm{K}$ Seungwon. Effect of Astragalus membranaceus extract on diabetic nephropathy. Endocrinology Diabetes \& Metabolism Case Report, 2014: 140063.

12. J Yingli, S Yan, Z Yinggang, M Chunsheng. Fenugreek prevents the development of STZ-induced dfiabetic nephropathy in a rat model of diabetes. Evidence Based Complementary and Alternative Medicine, 2014: 259368.

13. SU Chon, YM Kim, YJ Park, H Buk-Gu, P Yong-Seo, G Shela. Antioxidant and antiproliferative effects of methanol extracts from raw and fermented parts of mulberry plant (Morus alba L.). European Food Research Technology, 2009; 230: 231-237.

14. N Bahman, M Golboo. Influence of three Morus species extracts on $\alpha$ - amylase activity. Iranian Journal of Pharmaceutical Research, 2009; 8(2):115-119.

15. HIH El-Sayyad, MA El Sherbiny, MA Sobh, AM Abou-El-Naga , MA Ibrahim , SA Mousa. Protective effects of Morus alba leaves extract on ocular functions of pups from diabetic and hypercholesterolemic mother rats. Inernationalt Journal of Biological Scences, 2011; 7(6): 715-728.

16. K Doi, T Kojima, M Makino, Y Kimura, Y Fujimoto . Studies on the constituents of the leaves of Morus alba L. Chemical and Pharmaceutical Bulletin, 2001; 49:151-53.
17. $\mathrm{P}$ Trinder. Determination of blood glucose using an oxidaseperoxidase system with a non-carcinogenic chromogen. Journal of Clinical Patholology, 1969; 22(2):158-61.

18. NS Sudhakar, TN Pattabiraman. A new colorimetric method for the estimation of glycosylated haemoglobin. Clinical Chimical Acta. 1981; 109: 267-274.

19. A Hyvarinen, EA Nikkila.. Specific determination of blood glucose with o-toluidine. Clinical Chimical Acta, 1962; 7: 140143.

20. A Zlatkis, B Zal, AJ Boyle.. A new method for the direct determination of serum cholesterol. Journal of Laboratory Clinical Medicine, 1953; 41: 480-491.

21. LB Foster, RT Dunn.. Standard reagents for determination of serum triglycerides by colorimetric Hantzch condensation method. Clinical Chemistry, 1973; 19: 338-340.

22. WM Gidez, M Webb. Revision of cholesterol determination. Journal of Biochemistry, 1950; 187:77697-106.

23. L Jendrassik, P Grof.. Colorimetric method of determination of bilirubin. Biochem Z., 1938; 297: 81-82.

24. NW Tietz.. Fundamentals of Clinical Chemistry, Philadelphia, W.B. Saunders Company, 1996: pp 240.

25. BT Doumas, RI Arends. Pinto PC in standard methods of Clinical Chemistry. Academic Press Chicago, 1972; 7:175-189.

26. P Kakkar, D Ballabh, PN Vshwanathan. A modified spectrophotometric assay of superoxidesidumate.Inia journal of Biochemistry \& Biophysics, 1984; 21: 130-132.

27. AK Sinha.. Colourimetric assay of catalase. Analytical Biochemistry, 1972; 47: 389-394.

28. DJ Jollow, JR Michell, JR Gillete. Bromoibenzene-induced Liver necrosis: Protective role of glutathione and evidence for 3,4bromobenzene oxide as hepatotoxic metabolite. Pharmacology, 1974; 11: 151-169

29. H Ohkawa, N Ohishi, K. Yagi. Assay for lipid peroxides in animal tissues by thiobarbituric acid reaction. Analytical Biochemistry, 1979; 95: 351-358.

30. RA Drury, EA Wallington, R Cancerson.. Carlton's Histopathological Techniques, Oxford University Press, Oxford, UK, 4th edition. 1976: pp 345-789.

31. NK Ahmad, AK Rahmat, A Mushtaq, M Nadia. Role of antioxidant in oxidative stress and diabetes mellitus. J. Phar. Cog. Phytochem., 2015; 3(6): 217-220.

32. AE Ahmed, MH Fathalla, AG Salah, AG Salah, AN Ayman, A Essam. Methanolic extract of Marrubium vulgare ameliorates hyperglycemia and dyslipidemia in streptozotocin-induced diabetic rats. International Journal of Diabetes Mellitus, 2015; 3(1): 37-44.

33. SH Lee, SY Choi, H Kim, JS Hwang, BG Lee, JJ Gao.. Mulberroside F isolated from the leaves of Morus alba inhibits melanin biosynthesis. Biological and Pharmaceutical Buletinl, 2002; 25:1045-1048.

34. G Proctor, T Jiang, M Iwahashi.. Regulation of renal fatty acid and cholesterol metabolism, inflammation, and fibrosis in Akita and Ove 26 mice with type 1 diabetes. Diabetes, 2006; 55: 20522509.

35. AF Foyet, K René, EO Jean-Louis, NY Jeanne. Antidyslipidemic and antioxidant potentials of methanol extract of Kalanchoe crenata whole plant in streptozotocin-induced diabetic nephropathy in rats. Tropical Journal of Pharmaceutical Research, 2011; 11(5):767-775.

36. J Frey, M Daudon, N Raby et al.,Valeur séméiologique des paramètres biochimiques urinaires. AnnalesDe. Biologie. Clinique, 2001; 59:13-25.

37. K Sugimoto, K Sakamoto, A Fujimura.. Decrease in oral bioavailability of cyclosporin A by coadministration of probucol in rats. Life Science, 1997; 60:173-179.

38. TP Almdal, H. Vilstrup. Strict insulin treatment normalizes the organic nitrogen contents and the capacity of urea-N synthesis in experimental diabetes in rats. Diabetologica, 1988; 31:114-8.

39. M Koshikawa, M Mukoyama, K Mori. Role of p38 NitrogenActivated protein kinase activation in podocyte. Injury and proteinuria in experimental nephritic syndrome. Journal of American Society of Nephrology, 2005; 16: 2690-2701. 
Indo Global Journal of Pharmaceutical Sciences, 2019; 9(1): 25-31

40. T Ohtake, M Kimura.. Roles of reactive oxygen species and antioxidant enzymes in murine daunomycin-Induced nephropathy. J. Laboratory Clinical Medicine, 1997; 129: 81-88.

41. HE Seifried, DE Anderson, EI Fisher A review of the interaction among dietary antioxidants and reactive oxygen species. Journal of Nuritional Biochemistry, 2007; 18(9): 567-579.

42. DR Janero, Burghardt B.. Analysis of cardiac membrane phospholipid peroxidation kinetics as malondialdehyde: nonspecificity of thiobarbituric acid-reactivity. Lipids, 1988; 23 : $452-8$.

43. BF Schrijvers, AS Vriese.. Novel insights in the treatment of diabetic nephropathy. Acta. Clin. Belg., 2007; 62:278-90.

44. H Oh, EK Ko, JY Jun, MH Oh, SU Park, , KH Kang.. Hepatoprotective and free radical scavenging activities of prenylflavonoids coumarin and stilbene from Morus alba. Planta Medica, 2002; 68: 932-934.

45. KO Chung, BY Kim, MH Lee, YR Kim, HY Chung, JH Park.. In vitro and in-vivo anti-inflammatory effect of oxyresveratrol from Morus alba L. Journal of Pharmacy Pharmacology, 2003; 55:1695-1700.

Indo Global Journal of Pharmaceutical Sciences( ISSN 2249 1023; CODEN- IGJPAI; NLM ID: 101610675) indexed and abstracted in CrossRef (DOI Enabling), UGC CARE Journal List, EMBASE(Elsevier), National Library of Medicine (NLM) Catalog, ResearchGate, Publons, CAS (ACS), Index Copernicus, Google Scholar and many more. For further details, visit http://iglobaljournal.com 